\title{
A ética na pesquisa em educação: panorama e desafios pós-Resolução CNS no 510/2016
}

\author{
Ethics in education research: \\ overview and challenges post the CNS $n^{\circ}$ 510/2016 Resolution \\ La ética en la investigación en educación: \\ panorama y desafíos posteriores a la Resolución CNS nº 510/2016
}

\author{
JEFFERSON MAINARDES*
}

\begin{abstract}
RESUMO
O artigo apresenta um panorama da ética em pesquisa na área de educação e os principais desafios após a aprovação da Resolução CNS no 510/2016, que dispõe sobre as normas éticas aplicáveis a pesquisas de Ciências Humanas e Sociais. Argumenta-se que os atuais procedimentos e normas da revisão ética do Sistema CEP/Conep são altamente burocráticos e expressam uma visão utilitarista e limitada da ética em pesquisa. Ressalta-se, também, que essa ética necessita integrar o processo de formação de pesquisadores. E, para tal, é relevante a elaboração de um documento orientador da área de educação, com o objetivo de instrumentalizar os pesquisadores em relação a essa questão e aos dilemas envolvidos no atual sistema de revisão ética (Sistema CEP/Conep). O artigo revela que a criação desse sistema fora da área de saúde continua na pauta das associações científicas de Ciências Humanas e Sociais.
\end{abstract}

Palavras-chave: Ética na pesquisa. Pesquisa educacional. Associação Nacional de Pós-Graduação e Pesquisa em Educação Anped.

\begin{abstract}
This paper presents an overview of ethics in research in the area of education and the main challenges after the approval of the CNS (National Health Council) 510/2016 Resolution, which deals with the applicable ethical norms to Human and Social Sciences research. We argue that the current norms and procedures of the ethical review of the CEP/Conep (Committee for Ethics in Research/National Commission of Ethics in Research) System are highly bureaucratic and express a limited view of ethics in research. We also point out that ethics in research need to integrate the education process of researchers and that it would be relevant to elaborate a guiding document in the area of Education with the purpose of instrumentalizing the researchers of the area on the discussion of ethics in research and the dilemmas involved in the current ethical review system (CEP/Conep System). This paper indicates that the creation of a system of ethical review outside the area of Health continues on the agenda of the scientific associations of Human and Social Sciences.
\end{abstract}

Keywords: Ethics in research. Educational research. National Association of Postgraduate Studies and Research in Education Anped.

\section{RESUMEN}

El artículo presenta un panorama de la ética en la investigación en el área de educación y los principales desafíos emergentes luego de la aprobación de la Resolución CNS no 510/2016, que establece normas éticas aplicables a las investigaciones en Ciencias Humanas y Sociales. Se argumenta que los actuales procedimientos y normas de revisión ética del Sistema CEP/Conep son altamente burocráticos y expresan una visión utilitarista y limitada de la ética en la investigación. Además, se destaca que la ética necesita integrar los procesos de formación de los investigadores y, para esto, es importante la elaboración de un documento orientador del área educación, con el objetivo de instrumentalizar a los investigadores en relación a esta cuestión así como de abordar los dilemas implicados en el actual sistema de revisión ética (Sistema CEP/Conep). Este trabajo también revela que la creación de ese sistema, fuera del área de la salud, continúa en la pauta de las asociaciones científicas de las Ciencias Humanas y Sociales.

Palabras clave: Ética en investigación. Investigación educacional. Asociación Nacional de Posgrado e Investigación en Educación Anped.

\footnotetext{
* Professor adjunto do Departamento de Educação da Universidade Estadual de Ponta Grossa e International Alumni Ambassador - Alumni Association - Institute of Education/University of London. Coordenador do Programa de Pós-Graduação em Educação (Mestrado e Doutorado) da UEPG. E-mail: <jefferson.m@uol.com.br>
} 


\section{INTRODUÇÃO}

O objetivo deste artigo é apresentar um panorama da ética na pesquisa em educação e os principais desafios que a revisão ética coloca para os pesquisadores da área no contexto pós-Resolução CNS no - 510/2016, que dispõe sobre as normas aplicáveis a pesquisas em Ciências Humanas e Sociais (CHS).

A maior parte dos desafios da área da educação é compartilhada com outros campos que envolvem as Ciências Humanas e Sociais, devido ao fato de que, no Brasil, há uma regulamentação única da ética em pesquisa com seres humanos para as duas grandes áreas (biomédica e CHS). Esse fato traz inúmeras dificuldades para a pesquisa em CHS, apesar das constantes críticas de pesquisadores e associações científicas dessa área.

$\mathrm{O}$ artigo está dividido em três seções. Na primeira, apresenta-se um breve panorama da ética na pesquisa na área de educação. Em seguida, sintetizam-se os principais pontos da Resolução CNS no 510/2016, que dispõe sobre as normas éticas aplicáveis a pesquisas de CHS e, finalmente, indicam-se os principais desafios que a área de educação necessita enfrentar com relação ao assunto.

\section{A QUESTÃo dA ÉTICA NA PESQUISA NA ÁREA DE EDUCAÇÃO: UM BREVE PANORAMA}

Ética em pesquisa tem sido uma preocupação constante dos pesquisadores da área da educação, bem como da Associação Nacional de Pós-Graduação e Pesquisa em Educação (Anped) e dos Programas de Pós-Graduação em Educação. O problema central dos pesquisadores (e de pesquisadores de CHS em geral) refere-se ao caráter altamente burocrático da revisão ética no Brasil, o qual possui regras e procedimentos uniformes para a área da pesquisa biomédica e da pesquisa em CHS. Em decorrência desse desacordo entre a regra uniformizadora e as necessidades e características da pesquisa em CHS, os pesquisadores da área de educação têm mantido uma certa distância das questões da revisão ética, pelo menos dos procedimentos do sistema CEP/Conep ${ }^{1}$.

Em um levantamento realizado pelo Fórum Nacional de Coordenadores de Programas de Pós-Graduação em Educação (Forpred), em 2013 (FORPRED, 2013), o qual contou com a participação de 86 Programas de PósGraduação em Educação (PPGEs), constatou-se que em 48 a submissão dos projetos de pesquisa dos pós-graduandos

\footnotetext{
${ }^{1}$ As siglas CEP e Conep significam, respectivamente, Comitê de Ética em Pesquisa e Comissão Nacional de Ética em Pesquisa. O sistema CEP/ Conep foi criado no âmbito da Resolução CNS 466/2012, a qual aprovou as diretrizes e normas regulamentadoras de pesquisas envolvendo seres humanos. Nessa resolução foi criado o Sistema CEP/Conep e a Plataforma Brasil. A existência de CEPs já era prevista na Resolução 196/1996.
}

ao Comitê de Ética era obrigatória, principalmente para os doutorandos. Em outros 38, a submissão de projetos (mestrado e doutorado) era opcional. Apesar disso, os informantes relataram que os pesquisadores dos PPGEs (docentes e pós-graduandos) tinham dúvidas a respeito do sistema CEP/Conep e também muitas discordâncias das exigências feitas para a submissão de projetos na Plataforma Brasil. Alguns PPGEs relataram dificuldades para aprovação de projetos, e outros indicaram exigências consideradas inadequadas para um projeto de CHS, como sugestões de alteração na amostra, discordâncias sobre referencial teórico, alteração nos instrumentos de coleta, etc.

Um aspecto importante observado no levantamento do Forpred é que a ética era uma preocupação dos PPGEs e que estes realizavam eventos para a discussão sobre essa questão, momentos de encontro com membros dos CEPs e até mesmo orientações aos pós-graduandos sobre o processo de submissão. Embora os CEPs sigam as mesmas normas, deve-se ressaltar que alguns encontram-se mais preparados para compreender as especificidades da pesquisa em CHS, o que facilita a revisão dos protocolos dessa área. Isso está relacionado ao posicionamento dos coordenadores de CEPs, sua composição, visão institucional sobre pesquisa em CHS, etc.

$\mathrm{Na}$ área de educação, a Anped tem sido o principal espaço de debate sobre ética na pesquisa. Algumas das principais ações são apontadas a seguir. Em 2007, na 30aㅡ Reunião Anual da Anped, em Caxambu, reuniram-se os membros da Comissão de Ética na Pesquisa, na época formada por Maria Inês Marcondes de Souza (PUCRio), Carlos Roberto Jamil Cury (PUC-MG), Antonio Carlos Rodrigues de Amorim (Unicamp) e Olgaíses Maués (UFPA). Uma das propostas, apresentada pelo Prof. Cury, era a elaboração de uma resolução conjunta (CNS e CNE) ou apenas do CNE para a ética na pesquisa em $\mathrm{CHS}^{2}$. A referida comissão, embora não tenha sido oficialmente extinta, não recebeu o apoio necessário para a continuidade dos trabalhos.

Em 2012, na 35a Reunião Anual da Anped, em Porto de Galinhas, foi aprovada uma moção à Conep solicitando agilização da complementação à Resolução 466/2012. A proposta de moção foi apresentada pelo Forpred e aprovada na Assembleia da Anped.

Na 36a Reunião Anual da Anped, em Goiânia, foi realizada a sessão especial "Ética na pesquisa: princípios e procedimentos", que contou com a participação de Antônio Joaquim Severino (USP e Uninove), Isabel Cristina de Moura Carvalho (PUCRS) e Aníbal Gil Lopes (UFRJ e representante da Conep), sob a coor-

\footnotetext{
2 Ao longo do tempo, diversas associações de CHS (ABA, Anpocs, SBS, etc.) têm lutado pela criação de um sistema fora da área de saúde, por meio de uma regulamentação específica, que atenda às especificidades das CHS.
} 
denação de Jefferson Mainardes (UEPG e Forpred) ${ }^{3}$. Para essa sessão, o Forpred organizou uma consulta aos PPGEs, via Google Docs, para obter um panorama da situação da ética em pesquisa nestes (Forpred, 2013). Ainda na 36a Reunião Nacional, os GTs 7, 10, 23 e 15 propuseram uma sessão especial - "Questões éticas na pesquisa com crianças" -, que contou com a participação de Natália Fernandes (Universidade do Minho, Portugal) e Silvia Helena Vieira Cruz (UFC), sob a coordenação de Jader Janer Moreira Lopes (UFJF) 4 .

Até outubro de 2013, as ações da relacionadas à ética em pesquisa ocorreram de forma isolada das demais associações de CHS. A partir de outubro de 2013, a Anped foi convidada para participar do GT de CHS da Conep encarregado de elaborar uma complementação à Resolução 466/2012, referente à pesquisa em Ciências Humanas e Sociais. O referido GT era composto pela representação de 28 associações de CHS e coordenado por Iara Guerriero. A Anped foi representada por Jefferson Mainardes (UEPG), tendo como suplente Antônio Carlos R. Amorim, que assumiu a titularidade a partir de agosto de 2015. As ações desse GT culminaram com a aprovação da Resolução CNS no 510/2016 após inúmeros embates entre os membros do GT de CHS e a Conep 5 .

A Res. 510/2016, embora estabeleça princípios específicos para a ética na pesquisa em CHS, foi elaborada no interior da Conep, o que acarreta grandes limitações. Mesmo estando em vigor, seu pleno emprego somente será possível com a finalização de formulário específico de CHS (Plataforma Brasil) e com a aprovação de uma resolução que trata da tramitação no sistema CEP/Conep. Na Resolução 510/2016, a tramitação dos protocolos será diferenciada de acordo com a gradação de risco $(\S 1 \underline{0}$ do Art. 21). O Art. 21 indica os níveis de risco mínimo, baixo, moderado e elevado. No caso das pesquisas de risco mínimo, a expectativa é que sejam aprovadas e liberadas para realização após o preenchimento do formulário específico de CHS. Ao final do preenchimento, o próprio sistema classifica o nível de risco da pesquisa.

Em setembro de 2016, o GT de CHS foi desfeito pela Conep, a qual solicitou às associações que indicassem representantes para a instância de acompanhamento prevista na Resolução 510/2016. Houve uma articulação das associações, via Fórum das Associações de Ciências Humanas, Sociais e Sociais Aplicadas (FCHSSA),

\footnotetext{
${ }^{3}$ Os textos de Severino e Carvalho foram publicados na revista Práxis Educativa (SEVERINO, 2014; CARVALHO; MACHADO, 2014). Ver também o editorial da seção temática "Ética na pesquisa" (MAINARDES, 2014).

${ }^{4}$ Ver Fernandes (2016).

5 A respeito do processo de elaboração da Resolução no 510/2016, ver Duarte (2015), Guerriero e Bosi (2015), Sarti (2015) e Guerriero (2016). Uma síntese dos principais pontos da Resolução 510/2016 pode ser encontrada em Guerriero (2016). Uma análise das implicações para a área de educação pode ser encontrada em Mainardes (2016).
}

para uma indicação conjunta de representantes, tendo sido indicadas Ruth Bittencourt (Uece) e Selma Leitão (UFPE). A composição da instância de acompanhamento ficou assim constituída: Iara Guerriero (Conep), Adriano Félix (Conep), George Pimentel (Conep), Aline Oliveira (Conep), Carlos Tadeu Siepierski (indicação CEPs), Patricia Krieger Grossi (indicação CEPs), Selma Leitão (associações do GT CHS) e Ruth Bittencourt (associações do GT CHS). A missão dessa instância é realizar as adequações necessárias na Plataforma Brasil e desenvolver ações para implementar essa resolução.

A participação da Anped no GT foi um momento importante, pois a partir disso foi criado um espaço no Portal da Anped para a divulgação de notícias, indicação de textos, e-mail para contato, etc. Além disso, em 2013 a Anped passou a integrar o Fórum das Associações de CHSSSA, atualmente coordenado pelo Prof. Luciano Mendes de Faria Filho (UFMG). A atuação desse fórum é bastante ampla, cujas frentes de ação contemplam a luta pela manutenção e pela ampliação dos investimentos na pesquisa em CHS, ética na pesquisa, entre outros temas relevantes para as Ciências Humanas e Sociais. No que se refere à ética na pesquisa, o posicionamento tem sido o de apoiar as decisões tomadas pelos representantes das associações que atuaram no GT de CHS da Conep, bem como lutar para que a regulamentação da ética na pesquisa seja elaborada fora da área da saúde.

Em abril de 2015, a Anped criou uma comissão para fomentar o debate permanente sobre ética na pesquisa, formada por Jefferson Mainardes (UEPG), Antonio Carlos Amorim (Unicamp), Antonio Joaquim Severino (USP, Uninove), Irene Gilberto (Unisantos), João Batista Carvalho Nunes (Uece), Isabel Carvalho (PUCRS), Petronilha Beatriz G. Silva (UFSCar), Alfredo Veiga Neto (UFRGS) e Marcos Vilela Pereira (PUCRS). A primeira reunião presencial foi realizada em 10 de junho de 2015, na sede da Anped, no Rio de Janeiro. As finalidades definidas para a comissão foram as seguintes:

- Fomentar o debate sobre questões éticas na pesquisa em educação no âmbito da Anped (Comitê Científico, GTs da Anped, Forpred, PPGEs, Fepae e outros).

- Articular ações sobre as questões da ética na pesquisa, na pós-graduação e nas publicações científicas da área de educação.

- Assessorar a diretoria da Anped nas questões relacionadas à ética na pesquisa.

- Ampliar o diálogo sobre questões éticas com as demais associações científicas do campo das Ciências Humanas e Sociais.

- Propor políticas de apoio à pesquisa, a publicações e à realização de eventos e debates sobre a ética em educação. 
- Acompanhar e participar das discussões sobre a regulamentação da ética na pesquisa.

- Manter atualizadas as informações sobre ética na pesquisa no Portal da Anped.

Uma das ações realizadas pela comissão foi a conclamação dos pesquisadores da área de educação para participarem da "Consulta à sociedade" sobre a resolução de CHS elaborada pelo GT de CHS da Conep. A consulta foi realizada de 15 de julho até o início de setembro de 2015. Outra ação foi a realização de uma sessão conversa, na 37a Reunião Nacional da Anped (Florianópolis, 2015), a qual contou com a participação de João Batista Carvalho Nunes (Uece) e Luciano Mendes de Faria Filho (UFMG/ $\mathrm{CD}$ do $\mathrm{CNPq}$ ), sob a coordenação de Antônio Carlos Rodrigues Amorim (Unicamp).

No âmbito das reuniões científicas regionais, a questão da ética na pesquisa vem sendo debatida, como foi o caso da Anped Sul, realizada em Florianópolis (2014), e das reuniões científicas regionais do Sul e do Nordeste, em 2016.

Em setembro de 2016, na Unirio, a Anped realizou o seminário "Ética e pesquisa em educação: entre a norma e o compromisso". O objetivo do encontro era debater questões relacionadas à ética na pesquisa e definir um posicionamento da área sobre questões específicas. Um ponto de partida importante do seminário foi considerar que, na área de educação, embora algumas iniciativas tenham sido realizadas, o debate sobre ética na pesquisa é ainda inicial. Em outras áreas (antropologia, psicologia, sociologia e serviço social), houve um debate mais sistemático sobre essa temática, o que permitiu a definição de alguns consensos a respeito do tema.

No referido seminário, foram indicadas como tarefas necessárias:

- Ampliação do debate sobre ética na pesquisa, tanto no que se refere aos procedimentos na prática da pesquisa quanto ao estudo da regulamentação atual.

- Realização de pesquisas acadêmicas sobre ética na pesquisa na área de Educação.

- Ampliação de publicações, inclusive de textos que abordem aspectos práticos da ética na pesquisa.

Além disso, destacaram-se as principais questões que necessitam ser debatidas pela área, organizadas em quatro pontos:

1ㅇ - A área considera importante e necessária a revisão ética dos projetos de pesquisa?

$2^{\mathrm{O}}$ - A revisão ética dos projetos de pesquisa, no Brasil, tem sido regulamentada na área de Saúde (Conep, Conselho Nacional de Saúde, Ministério da Saúde). A principal queixa das associações científicas da área de Ciências Humanas e Sociais é que tal sistema não atende (ou atende apenas parcialmente) às peculiaridades da área de Ciências Humanas e Sociais. O Fórum das Associações de CHSSA adverte que a regulamentação e a revisão ética sejam realizadas fora da área de Saúde. Qual a posição da Anped?

3으 - Enquanto a regulamentação e a revisão ética estiverem atreladas à Saúde, qual o posicionamento da área a respeito da legislação atual (Resolução 510/2016)? A Anped apoia a ideia de que a tramitação dos processos deve estar relacionada ao nível de risco (mínimo, baixo, moderado e elevado)? A Anped apoia a ideia de que as pesquisas classificadas como de risco mínimo sejam aprovadas e liberadas para realização? A Anped apoia a ideia de que é fundamental a criação de CEPs de Ciências Humanas e Sociais, ligados ao sistema CEP/ Conep? A Anped apoia a ideia de que é fundamental que os CEPs existentes tenham mais representantes da área de Educação e de CHS em geral?

4ㅇ-Com relação à exigência de protocolos do sistema CEP/Conep de periódicos e por agências de fomento, tem-se considerado que tal exigência não deve ser feita, enquanto a Resolução CNS no 510/2016 estiver em plena vigência, com a finalização do formulário próprio de CHS e da definição da tipificação de risco e tramitação dos protocolos de acordo com o nível de risco. Ou, ainda, com a criação de um sistema de revisão ética fora da área de Saúde. A Anped apoia que os periódicos e agências de fomento não exijam o protocolo do Sistema CEP/Conep? Quais as alternativas que poderiam ser construídas na área?

Buscou-se, ainda, no seminário, indicar alternativas a essas questões. No entanto, estas precisam resultar do consenso construído pelo coletivo dos pesquisadores da área.

\section{A RESOLUÇÃo CNS № 510/2016 E SUAS IMPLICAÇÕES PARA A PESQUISA}

Desde 2001, algumas associações de Ciências Humanas e Sociais (CHS), tal como a Associação Brasileira de Antropologia (ABA), vêm criticando a regulamentação centralizada e baseada no modelo biomédico, que acarreta sérias limitações para a revisão ética dos protocolos de pesquisa da área de CHS. Em virtude dessas críticas, e também com a participação de associações na consulta pública da Resolução 466/2012, ficou estabelecido que "[...] as especificidades éticas das pesquisas nas ciências sociais e humanas e de outras que se utilizam de metodologias próprias dessas áreas serão contempladas em resolução complementar, dadas suas particularidades" (BRASIL, 2013, p. 62).

Em agosto de 2013, a Conep convidou algumas associações de CHS para iniciar um Grupo de Trabalho (GT) com o objetivo de elaborar a citada resolução 
complementar. Após inúmeras reuniões com os membros do GT, formado por representantes de diversas associações de CHS, foi aprovada a Resolução CNS no 510/2016, que dispõe sobre as normas éticas aplicáveis a pesquisas de $\mathrm{CHS}^{6}$. No entanto, para a sua plena efetivação, é necessário que sejam feitas alterações na Plataforma Brasil, com a inclusão de um formulário próprio de CHS. Além disso, faz-se necessário aprovar, no âmbito da Conep, a resolução que trata de risco (de acordo com o nível) e tramitação de protocolos.

Apesar dessas iniciativas, o problema da revisão ética persiste para as CHS. As normas e os regulamentos continuam sendo elaborados pela Conep, que conta com poucos representantes das CHS. A seguir, destacam-se os principais pontos da Resolução CNS 510/2016.

O Art. 10 adverte que não serão registradas nem avaliadas pelo sistema CEP/Conep as pesquisas de opinião pública com participantes não identificados; as que utilizam informações de acesso público; as que utilizam informações de domínio público; as pesquisas com bancos de dados, cujas informações são agregadas; as pesquisas de revisão de literatura, atividade realizada com o intuito de ensino ou treino (alunos de graduação, curso técnico ou profissionais em especialização). Os Trabalhos de Conclusão de Curso de Graduação devem ser submetidos ao sistema CEP/Conep. No entanto, o Art. 27 diz que a pesquisa realizada por alunos de graduação e de pós-graduação, que seja parte de projeto do orientador já aprovado pelo sistema CEP/Conep, pode ser apresentada como emenda ao projeto aprovado, desde que não contenha modificação essencial nos objetivos e na metodologia do projeto original.

O Art. 15 trata do consentimento e do assentimento, os quais podem ser dispensados com a devida justificativa. $\mathrm{O}$ registro do consentimento e do assentimento pode ser feito de formas variadas (escrita, sonora, imagética, entre outras).

O Art. 21, § 1ํㅡ, de alta relevância, determina que a tramitação dos protocolos será diferenciada de acordo com a gradação de risco. A definição de risco e de gradação de risco ainda deverá ser aprovada na Conep e no CNS. No entanto, a proposta é finalizar um formulário próprio para a área de CHS, o qual deverá avaliar o grau de risco da pesquisa. As pesquisas de risco mínimo deverão ser aprovadas e liberadas para realização. Já as de risco baixo deverão ser analisadas por parecerista de um CEP. As pesquisas de risco moderado deverão ser analisadas e aprovadas pela plenária do CEP. E as de risco elevado, apreciadas pela Conep ou pelos CEPs acreditados.

\footnotetext{
${ }^{6}$ A respeito do processo de elaboração da Resolução no 510/2016, ver Duarte (2015), Guerriero e Bosi (2015), Sarti (2015), Guerriero (2016). Uma síntese dos principais pontos da Res. 510/2016 pode ser encontrada em Guerriero (2016); e uma análise das implicações para a área de educação, em Mainardes $(2016,2017)$
}

O Art. 25 assegura que a avaliação a ser feita pelo Sistema CEP/Conep incidirá sobre os aspectos éticos dos projetos, considerando os riscos e a devida proteção dos direitos dos participantes da pesquisa. A avaliação científica deverá ser avaliada por comissões acadêmicas de pesquisa, bancas de pós-graduação e instituições de fomento à pesquisa. Não cabendo ao sistema $\mathrm{CEP} / \mathrm{Conep}$ a análise do desenho metodológico em si (apenas quando impliquem riscos aos participantes). No Art. 26, adverte-se que a análise ética dos projetos somente deverá ser realizada em Comitês de Ética em Pesquisa que possuam representação equânime de membros de CSH.

Para que a resolução possa ter um efeito adequado, o Art. 30 indica a necessidade de estimular a participação de membros de CHS nos CEPs e a criação de novos comitês de ética em pesquisa (de CHS). Esta seria uma alternativa válida para evitar os problemas que têm ocorrido na revisão ética. Por outro lado, pode reforçar o sistema CEP/Conep, o qual tem sido bastante questionado pelos pesquisadores de CHS. Já o Art. 33 atesta que a composição da Conep necessita de equidade entre a área de humanas e sociais e as demais (biomédica).

Os passos seguintes à aprovação envolvem a finalização do formulário próprio para as pesquisas de CHS (ou adaptações no formulário da grande área de Ciências Humanas, na Plataforma Brasil) e a aprovação da resolução sobre tramitação de protocolos de acordo com o nível de risco. Sem essas duas medidas, a efetividade da Resolução 510/2016 fica bastante prejudicada.

O processo de elaboração da resolução foi bastante tenso entre os representantes das associações no GT de CHS, pela diversidade de visões acerca das questões éticas e quanto ao Conep. Assim também foi a relação com a coordenação e com a plenária da Conep, em virtude dos encaminhamentos e das diferenças existentes entre a concepção de revisão ética do modelo biomédico e as demandas e necessidades dos pesquisadores de CHS.

Pôde-se compreender nesse processo que a área de $\mathrm{CHS}$ não possui autonomia dentro do sistema $\mathrm{CEP} / \mathrm{Conep}$ e necessita do aval da Conep, majoritariamente formado por representantes associados à visão biomédica de ética na pesquisa e do seu processo de revisão. Nesse quadro, a elaboração e finalização da resolução dependeu de negociações, debates e embates para chegar a uma versão possível de ser aprovada e encaminhada ao CNS.

Embora a coordenação e os membros da Conep considerem que se trata de um sistema descentralizado, que apenas recebe os processos via Plataforma Brasil e os destina aos CEPs, pode-se considerar que se trata de uma estrutura altamente centralizada, uma vez que a Conep é o órgão que aprova as regulamentações do sistema.

A luta para que a avaliação ética das pesquisas de CHS seja realizada fora da área da saúde não é recente. 
Em 2004, Vilma Figueiredo, então vice-presidente da Sociedade Brasileira para o Progresso da Ciência (SBPC), já indicava a necessidade de criação de uma Comissão Nacional de Ética em Pesquisa vinculada ao CNPq. Segundo Figueiredo (2004):

\begin{abstract}
Existe no país, instituído há relativamente pouco tempo com forte apoio da comunidade científica, um Conselho de Ciência e Tecnologia - CnC\&T, presidido pelo presidente da República, integrado por membros de diferentes Ministérios e por representantes da sociedade civil, incluindo cientistas e industriais. A este Conselho deveria estar vinculada uma Comissão Nacional de Ética em Pesquisa. O que não soa convincente é a existência de uma Comissão necessariamente multidisciplinar abrigada em um Conselho de área específica vinculado a um Ministério de competência tópica (FIGUEIREDO, 2004, p. 116).
\end{abstract}

Posteriormente, em 2013, a ABA e a Associação Nacional de Pós-Graduação e Pesquisa em Ciências Sociais (Anpocs) apresentaram oficialmente a proposta da criação de um sistema de avaliação ética no Ministério de Ciência e Tecnologia (DUARTE, 2017). Atualmente, o Fórum das Associações de CHSSA tem continuado a luta para que a avaliação ética seja realizada fora da área da Saúde 7 .

\section{ÉTICA NA PESQUISA EM EDUCAÇÃO: DESAFIOS ATUAIS}

Conforme afirmado, a Resolução CNS no 510/2016 contempla questões específicas da pesquisa em CHS. Apesar disso, possui limitações e traz as marcas de uma regulamentação elaborada no âmbito da Conep e do modelo biomédico. Como afirmado, o pleno funcionamento dessa resolução somente será possível em sua plenitude após a implantação de um formulário específico de CHS, elaborado pelo GT de CHS da Conep e pelos representantes das associações (ou após alterações radicais na Plataforma Brasil, com a criação de um tronco específico de CHS). Devendo ter ainda a aprovação de uma resolução sobre tramitação de protocolos no sistema CEP/Conep, que contemple e garanta que a tramitação seja baseada no nível de risco. A criação de CEPs específicos de CHS pode reduzir as dificuldades que alguns pesquisadores enfrentam para aprovar protocolos de pesquisa em CHS. Por outro lado, essa alternativa pode fortalecer a ideia de que a regulamentação da ética em pesquisa deva estar atrelada à Conep e à área de saúde.

\footnotetext{
${ }^{7}$ Um levantamento bastante completo da luta pela regulamentação da revisão ética fora da área da saúde é apresentado por Duarte (2017).
}

A seguir, sintetizam-se os principais desafios da ética em pesquisa na área de educação.

\section{1o Ética em pesquisa para além da regulamentação}

Santos (2017) explora três níveis de ética: a ética das normas, a ética de princípios e a ética de relação. Para o autor, o primeiro nível da ética é normativo (o menos profundo); o segundo, interior; e o terceiro é relacional ou inter-humano Esse nível - de profundidade radical "[...] é o da ética de relação, inspirado na disposição de deixar-se afetar e responsabilizar-se por outrem, com suas necessidades, exigências e limites únicos. A categoriachave - ou centro gerador do dever - é a de alteridade" (SANTOS, 2017, p. 9 - grifos do autor).

Esses três níveis de ética são extremamente úteis para se compreender a necessidade de superação da ideia de ética na pesquisa apenas como uma norma a ser seguida ou como o preenchimento de um formulário. $\mathrm{Na}$ verdade, a ética na pesquisa necessita ser entendida como um "problema de formação". Isso significa que precisa ser trabalhada com os alunos na graduação e na pós-graduação, ser debatida e problematizada nos Grupos de Pesquisa, nas sessões de orientação, nas defesas de mestrado e doutorado e em outros espaços, bem como na divulgação de resultados de pesquisa. A ideia da ética na pesquisa como o preenchimento de um formulário é totalmente insuficiente no que se refere ao emprego de uma ética reflexiva, a ética dos princípios e a ética de relação.

A pesquisa de Nunes (2016) tem indicado a incipiente presença da ética na pesquisa, nas disciplinas de pósgraduação. Nesse sentido, é louvável a iniciativa da criação da linha de pesquisa "A regulação da ética na pesquisa como problema de formação", no Grupo de Pesquisa "Educação: ofício, artesanato e illusio", cadastrado no CNPq e liderado por Mónica de la Fare e Isabel Cristina de Moura Carvalho (PUCRS).

\section{2o Publicação de textos sobre ética na pesquisa}

O segundo desafio está associado ao primeiro. Trata-se da necessidade de realização de pesquisas sobre ética na pesquisa, bem como de publicação de textos que abordem aspectos relacionados aos princípios e aos procedimentos da ética na pesquisa em CHS.

São ainda escassos os textos em língua portuguesa sobre a ética na prática da pesquisa ${ }^{8}$. Há uma carência de textos que abordem os princípios da ética em pesquisa e

\footnotetext{
8 Destacam-se como relevantes as normas éticas e legais em publicações da APA (APA, 2012) e do documento do CNPq - Ética e Integridade na Prática Científica (CNPq, 2011). Ver também o Anexo A deste artigo.
} 
temas como confidencialidade; consentimento; anonimato; conflitos de interesse, vulnerabilidade; arquivamento de dados; identidade, poder e posição (hierarquia); questões éticas na análise de dados (rigor, honestidade, validade); pesquisa em espaços on-line; plágio; aspectos éticos na editoração e publicação; aspectos éticos na orientação e tutoria, etc.

Além da publicação de textos, ressalta-se que seria relevante a tradução de textos sobre ética, publicados em língua estrangeira. Na língua inglesa, há uma variedade de materiais sobre esse tema (e.g. BROOKS; RIELE; MAGUIRE, 2014; McNAMEE; BRIDGES, 2002). Além de livros, capítulos e artigos, os códigos de ética ou documentos orientadores elaborados pelas Associações de Pesquisa em Educação de países como Austrália, Alemanha, Escócia, Estados Unidos e Inglaterra constituem-se em materiais valiosos para a formação de pesquisadores (AARE, 1993; DGfE, 1999; SERA, 2005; AERA, 2011; BERA, 2011). Nesses países, a avaliação ou revisão ética dos projetos de pesquisa é realizada por comitês e comissões de ética em pesquisa das instituições, com base nos documentos da associação. E é mais valorizada a aplicação dos princípios da ética em pesquisa, bem como a reflexividade e a discussão a respeito dos dilemas éticos envolvidos.

Em um levantamento de publicações relevantes para a discussão sobre ética na pesquisa em CHS e em educação (Anexo A), constatou-se que, dos 93 textos incluídos no levantamento, 40 referiam-se a questões de regulamentação $(43 \%)$. Os demais tratavam da aplicação da ética na pesquisa em contextos específicos - crianças, adolescentes, famílias, gênero e sexualidade, pesquisa com imagens, educação matemática, com 27 textos (29\%); discussões sobre os fundamentos da ética na pesquisa, com 18 textos $(19,3 \%)$; questões relacionadas ao plágio e à publicação, com cinco textos $(5,4 \%)$; ética e formação de pesquisadores, com dois textos $(2,2 \%)$; e ética na prática da pesquisa, com um texto $(1,1 \%)$.

A elevada incidência de textos sobre regulamentação está relacionada aos problemas e dificuldades que os pesquisadores de CHS enfrentam no processo de revisão ética. Isso significa que estes, interessados em debater questões sobre a ética na pesquisa, ocupam-se mais do debate sobre a regulamentação, visto ser este um dos principais entraves, restando pouco tempo e energia para desenvolver outras temáticas necessárias, tais como os fundamentos e princípios da ética e a sua aplicação na prática da pesquisa. É também relevante ressaltar que, dos 93 textos incluídos no levantamento, poucos abordam a ética na pesquisa em educação. Trata-se de um tema ainda pouco explorado na área de educação. Somente recentemente algumas revistas publicaram dossiês ou seções temáticas sobre o assunto. ${ }^{9}$

\section{$3^{0}$ A necessidade da definição de orientações gerais para a área de Educação}

Conforme mencionado em alguns países, as orientações sobre ética na pesquisa são definidas pelas associações científicas da área de educação. São documentos que apresentam orientações gerais sobre diversos aspectos relacionados à ética da pesquisa em sua prática. A elaboração de um documento dessa natureza é complexa e desafiadora, mas constitui-se em um espaço importante para que as associações possam avançar em termos da definição de princípios gerais e de enfretamento dos dilemas éticos da área.

O Código de Ética da Associação Australiana de Pesquisa Educacional (AARE, 1993) ressalva que o texto produzido pela associação é um documento orientador da conduta ética na pesquisa e serve como um ponto de partida para reflexões posteriores. Não é um conjunto de "leis" (AARE, 1993). A intenção é que os procedimentos éticos sejam incorporados como práticas reflexivas e conscientes. $\mathrm{O}$ documento da Aare destaca a necessidade de evitar-se o exagero ou a sub-representação dos dados, o que implica o rigor e a honestidade na análise de dados e a elaboração de relatórios. Requer também que se preste atenção às limitações dos resultados no que se refere à confiabilidade e à aplicabilidade. Os pesquisadores não devem exagerar na significância de seus resultados nem subestimar suas implicações práticas e políticas. Não devem também fabricar, falsificar ou intencionalmente sub-representar evidências, dados, achados e conclusões. Precisam elaborar relatórios completos sem omissões de dados significativos, revelando detalhes de suas teorias, de seus métodos e de seus desenhos de pesquisa que estão subjacentes às interpretações dos seus achados.

\footnotetext{
9 A esse respeito, ver:

a) Seção temática "Ética na Pesquisa", publicada na revista Práxis Educativa (v. 9, n. 1, 2014);

b) Dossiê: Ética e história oral", publicado na revista História Oral (v. 17, n. 2, 2014);

c) Editorial da revista Educação \& Sociedade (v. 36, n. 133, 2015);

d) Dossiê "Ética, pesquisa, história: desafios na produção do conhecimento", publicado na revista História e Perspectiva (v. 28, n. 52, 2015);

e) Seção temática "Estudos e pesquisas com crianças: desafios éticos e metodológicos", publicada na revista Currículo sem Fronteiras (v. 15, n. 1, 2015);

f) Dossiê "Comitês de Ética em Pesquisa: caminhos e descaminhos teóricometodológicos", publicado na Revista Brasileira de Sociologia (v. 3, n. 5, 2015);

g) Dossiê "Ética e pesquisa com imagens", publicado na revista Teias (v. 14, n. 42, 2015); e

h) Seção temática "A ética na pesquisa em Ciências Humanas e Sociais: continuando o debate, publicada na revista Práxis Educativa (v. 12 $\mathrm{n}, 1,2017)$
} 
O Código da Aare destaca quatro princípios básicos: a) as consequências da pesquisa devem reforçar o bemestar geral; b) os pesquisadores necessitam reconhecer que a pesquisa educacional é uma questão ética e que seu propósito deve ser o desenvolvimento dos bens humanos; c) nenhum risco ou prejuízo deve ser tolerado a menos que seja remediável após informar o participante do risco; d) deve haver respeito à dignidade e ao valor das pessoas e bem-estar dos participantes. Esse documento australiano explicita princípios específicos, como risco, consentimento, confidencialidade, pesquisa sobre grupos, publicação, pesquisa em instituições, responsabilidade social, propriedade e autoria, formação de pesquisadores.

Também o Código de Ética da Associação Americana de Pesquisa Educacional (Aera) é bastante completo. Trata-se de um documento aprovado em 2011 e publicado na revista Educational Researcher (v. 40, n. 3, p. $145-156,2011)$. O documento possui 12 páginas e é dividido em 22 seções. Esse código destina-se a fornecer tanto os princípios quanto as regras para cobrir situações profissionais encontradas pelos pesquisadores em educação. Tem como principal objetivo o bem-estar e a proteção dos indivíduos e dos grupos com os quais os pesquisadores em educação trabalham. É também um documento utilizado na formação dos futuros pesquisadores em educação e outros pesquisadores que se beneficiariam do entendimento dos princípios e dos padrões éticos que orientam pesquisadores em educação em seu trabalho profissional. O documento determina que "[...] é de responsabilidade individual de cada pesquisador em educação aspirar aos mais altos padrões de conduta possíveis em matéria de investigação, ensino, prática e serviço" (AERA, 2011, p. 146). Define cinco princípios que devem orientar os pesquisadores em educação na determinação do curso de ações éticas em vários contextos, a saber: a) competência profissional; b) integridade; c) responsabilidade profissional, científica e do conhecimento; d) respeito aos diretos, à dignidade das pessoas e à diversidade; e e) responsabilidade social (BERA, 2011). Os padrões éticos abordam 22 itens, entre diversos aspectos: a) fabricação, falsificação e plágio; b) prevenção de danos; c) não discriminação; f) não exploração; g) assédio; h) conflitos de interesse; i) confidencialidade; j) anonimato das fontes; k) consentimento livre e esclarecido; 1) consentimento livre e esclarecido de estudantes e subordinados; m) consentimento livre e esclarecido com crianças; n) uso de fraude em pesquisa; o) oportunidades de pesquisa inesperadas; p) compartilhamento de dados; q) créditos de autoria; r) publicação duplicada de dados; s) responsabilidades dos editores; t) responsabilidades dos revisores; u) tratamento justo das partes em disputas éticas; v) cooperação com comitês de ética.
O documento da Associação Britânica de Pesquisa Educacional (BERA, 2011) apresenta os seguintes princípios que fundamentam suas orientações éticas: respeito à pessoa, respeito ao conhecimento, respeito aos valores democráticos, respeito à qualidade da pesquisa educacional, respeito à liberdade acadêmica. Apresenta as responsabilidades do pesquisador com os participantes; com os financiadores; com a comunidade de pesquisadores educacionais; com os profissionais da educação; com os formuladores de políticas; e com o público em geral.

Como qualquer código de ética ou documento orientador com relação a boas práticas de pesquisa, o documento das associações científicas de educação são constantemente revisados. A existência de um código ou documento orientador é essencial para a definição de critérios éticos a serem seguidos pelos pesquisadores da área. O ponto principal desse documento é que, além de orientar a prática da pesquisa, serve para a formação de futuros pesquisadores. Uma das decisões do seminário "Ética e pesquisa em educação: entre a norma e o compromisso" foi a elaboração de um documento geral que pudesse instrumentalizar os pesquisadores da área sobre a discussão da ética na pesquisa e dos dilemas envolvidos no atual sistema de revisão ética (Sistema CEP/Conep).

\section{CONSIDERAÇõES FINAIS}

Neste artigo, apresenta-se um panorama da ética na pesquisa em educação e os principais desafios para essa área. Revela-se que o processo de revisão ética vigente no Brasil é altamente burocrático, utilitarista e fortemente baseado no modelo biomédico. Desse modo, a revisão ética realizada nos CEPs de algumas instituições mostra-se inadequada para os pesquisadores da área. Além disso, ressalta-se que o referido procedimento expressa uma visão limitada da ética em pesquisa (preenchimento de um formulário). Para além das preocupações com as normas e procedimentos da revisão ética, considera-se essencial conceber a ética na pesquisa como uma questão de formação, que envolve o estudo e a discussão da ética na pesquisa na graduação e na pós-graduação (princípios e procedimentos). Observa-se, também, a importância da realização de pesquisas sobre ética na pesquisa, bem como a necessidade de ampliar as publicações sobre esse tema, incluindo a abordagem de questões cruciais da ética da pesquisa, a partir da prática da pesquisa e dos dilemas enfrentados pelos pesquisadores.

Diante do quadro atual de revisão ética da pesquisa em CHS, constata-se que a criação de um sistema de revisão ética fora da área de saúde necessita ser mantido na pauta das associações científicas de CHS, principalmente pelo Fórum das Associações de CHSSA. Ao lado dessa 
luta, afirma-se que a área de educação necessita avançar nas discussões sobre ética em pesquisa, uma vez que a elaboração de um código de ética ou de um documento orientador pelas próprias associações científicas (no caso brasileiro, pela Anped, com a colaboração de outras associações) é uma outra possibilidade para a resolução do conflito entre a norma atual e o compromisso da área com as questões éticas.

\section{REFERÊNCIAS}

AARE. Australian Association for Research in Education. AARE Code of Ethics, 1993. Disponível em: < http://www.aare. edu.au/pages/aare-code-of-ethics.html>. Acesso em: 1 fev. 2017.

AERA. Code of Ethics - American Educational Research Association. Educational Researcher, v. 40, n. 3, p. 145-156, 2011. doi:10.3102/0013189x11410403

APA. American Psychological Association. Normas éticas e legais em publicações. In: APA. Manual de publicação da APA. 6. ed. Porto Alegre: Penso, 2012.

BERA. British Educational Research Association. Ethical guidelines for educational research. London: Bera, 2011.

BRASIL. Conselho Nacional de Saúde. Resolução no 466, de 12 de dezembro de 2012. Diário Oficial da União, Poder Executivo, Brasília, DF, 13 jun. 2013. Seção 1, n. 112, p. 59-62.

Conselho Nacional de Saúde. Resolução no 510, de 7 de abril de 2016. Diário Oficial da União, Poder Executivo, Brasília, DF, 24 maio 2016. Seção 1, n. 98, p. 44-46.

BROOKS, Rachel; RIELE, Kitty; MAGUIRE, Meg. Ethics and education research. London: Bera, Sage, 2014.

CARVALHO, Isabel Cristina de Moura; MACHADO, Frederico Viana. A regulação da pesquisa e o campo biomédico: considerações sobre um embate epistêmico desde o campo da educação. Práxis Educativa, Ponta Grossa, v. 9, n. 1, p. 209-234, jan./jun. 2014. doi:10.5212/praxeduc.v.9i1.0010

CNPQ. Conselho Nacional de Desenvolvimento Científico e Tecnológico. Ética e integridade na prática científica. Brasília: CNPq, 2011.

DGfE. Deutsche Gesellschaft für Erziehungswissenschaft. Code of Ethics of Deutsche Gesellschaft für Erziehungswissenschaft. Berlin: DGfE, 1999. Disponível em: <http:// www.dgfe.de/en/service/code-of-ethics.html>. Acesso em: 8 fev. 2017.

DUARTE, Luiz Fernando Dias. Ética em pesquisa nas ciências humanas e o imperialismo bioético no Brasil. Revista Brasileira de Sociologia, Porto Alegre, v. 3, n. 5, p. 31-52, jan./jun. 2015. doi:10.20336/rbs.90

DUARTE, Luiz Fernando Dias. Cronologia da luta pela regulação específica da avaliação da ética em pesquisa no Brasil. Práxis Educativa, v. 12, n. 1, jan./abr. 2017.

FERNANDES, Natália. Ética na pesquisa com crianças: ausências e desafios. Revista Brasileira de Educação, Rio de
Janeiro, v. 21, n. 66, p. 759-779, jul./set. 2016. doi:10.1590/ s1413-2478201621639

FIGUEIREDO, V. Ética e ciência: comissões de ética em pesquisa científica. In: VÍCTORA, C. et al. (Orgs.). Antropologia e ética: o debate atual no Brasil. Niterói: EdUFF, p. 113-118, 2004.

FORPRED. Fórum Nacional de Coordenadores de Programas de Pós-Graduação em Educação. Levantamento sobre Ética na Pesquisa nos Programas de Pós-Graduação em Educação, 2013. (Inédito).

GUERRIERO, Iara Coelho Zito. Resolução no 510, de 7 de abril de 2016, que trata das especificidades éticas das pesquisas nas ciências humanas e sociais e de outras que utilizam metodologias próprias dessas áreas. Ciência \& Saúde Coletiva, Rio de Janeiro, v. 21, n. 8, p. 2619-2629, ago. 2016. doi: 10.1590/1413-81232015218.17212016

GUERRIERO, Iara Coelho Zito; BOSI, Maria Lucia M. Ética em pesquisa na dinâmica do campo científico: desafios na construção de diretrizes para ciências humanas e sociais. Ciência \& Saúde Coletiva, Rio de Janeiro, v. 20, n. 9, p. 26152624, 2015. doi:10.1590/1413-81232015209.06022015

MAINARDES, Jefferson. Apresentação - Seção Temática "Ética na Pesquisa". Práxis Educativa, Ponta Grossa, v. 9, n. 1, p. 197-198, jan./jun. 2014

MAINARDES, Jefferson. A ética na pesquisa em Educação: desafios atuais. In: CARVALHO, M. V. C. de; CARVALHÊDO, J. L. P.; ARAUJO, F. A. M. Caminhos da Pós-Graduação em Educação no Nordeste do Brasil: avaliação, financiamento, redes e produção científica. Teresina: Edufpi, 2016. p.73-82. Disponível em: <https://www.researchgate.net/profile/ Jefferson_Mainardes>. Acesso em: 31 jan. 2017.

MCNAMEE, Mike; BRIDGES, David. The ethics of educational research. London: Blackwell, 2002.

NUNES, João Batista Carvalho. Formação de pesquisadores em educação para a ética em pesquisa. In: CARVALHO, Maria Vilani Cosme de; CARVALHÊDO, Josania Lima Portela; ARAUJO, Francisco Antonio Machado. Caminhos da PósGraduação em Educação no Nordeste do Brasil: avaliação, financiamento, redes e produção científica. Teresina: Edufpi, 2016. p. 59-71.

SANTOS, Luciano. Da competência no fazer à responsabilização no agir: ética e pesquisa em Ciências Humanas. Práxis Educativa, Ponta Grossa, v. 12, n. 1, 2017.

SARTI, Cynthia. A ética em pesquisa transfigurada em campo de poder: notas sobre o sistema CEP/Conep. Revista Brasileira de Sociologia, Porto Alegre, v. 3, n. 5, p. 79-96, jan./jun. 2015. doi: $10.20336 /$ rbs. 94

SERA. Scottish Educational Research Association. Ethical Guidelines for Educational Research. 2005. Disponível em: $<$ http://www.sera.ac.uk/documents/Publications/SERA\%20 Ethical\%20GuidelinesWeb.PDF>. Acesso em: 8 fev. 2017.

SEVERINO, Antônio Joaquim. Dimensão ética da investigação científica. Práxis Educativa, Ponta Grossa, v. 9, n. 1, p. 199208, jan./jun. 2014. doi:10.5212/praxeduc.v.9i1.0009 


\section{Anexo A \\ Levantamento das publicações sobre Ética em Pesquisa em CHS e em Educação (93 textos)}

\section{1 - Questões e debates sobre regulamentação da ética em pesquisa (40 textos)}

AMARAL FILHO, F. S. Ética e pesquisa nas Ciências Humanas e Sociais: um caso a ser pensado. Práxis Educativa, Ponta Grossa, v. 12, n.1, jan./abr. 2017.

BARBOSA, A. S.; CORRALES, C. M.; SILBERMANN, M. Controvérsias sobre a revisão ética de pesquisas em ciências humanas e sociais pelo Sistema CEP/Conep. Revista Bioética, v. 22, n. 3, p. 482-92, 2014.

CARVALHO, I. C. M.; MACHADO, F. V. A regulação da pesquisa e o campo biomédico: considerações sobre um embate epistêmico desde o campo da educação. Práxis Educativa, Ponta Grossa, v. 9, n. 1, p. 209-234, jan./jun. 2014.

COSTA, G.; CARTAXO, R.; BARBOSA, M.; CELINO, S. Conhecimento de docentes universitários sobre a atuação do comitê de ética em pesquisa. Revista Bioética, Brasília, v. 20, n. 3, p. 468-78, 2012.

CURY, C. R. J. Alguns apontamentos legais em torno da ética na pesquisa. Revista História e Perspectiva, Uberlândia, v. 28, n. 52, p. 39-50, jan./jul. 2015.

DINIZ, D. A pesquisa social e os comitês de ética no Brasil. In: FLEISCHER, S.; SCHUCH, P. (Orgs.). Ética e regulamentação na pesquisa antropológica. Brasília: Letras Livres e Editora da UnB, 2010. p. 183-192.

DUARTE, L. F. D. Práticas de poder, política científica e as ciências humanas e sociais: o caso da regulação da ética em pesquisa no Brasil. História Oral, v. 17, n. 2, p. 9-29, jul./dez. 2014.

. Ética em pesquisa nas Ciências Humanas e o imperialismo bioético no Brasil. Revista Brasileira de Sociologia, v. 3, n. 5, p. 31-52, jan./jun. 2015.

. Cronologia da luta pela regulação específica para as ciências humanas e sociais da avaliação da ética em pesquisa no Brasil. Práxis Educativa, Ponta Grossa, v. 12, n. 1, jan./abr. 2017.

EDITORIAL. Revisão ética na pesquisa em ciências humanas e sociais. Educação \& Sociedade, Campinas, v. 36, n. 133, p. 857-863, out./dez. 2015.

EDLER, F. A húbris bioética: rumo a uma polícia epistemológica? Revista Brasileira de Sociologia, v. 3, n. 05, p. 97-113, jan./jun. 2015.

FLEISCHER, S.; SCHUCH, P. (Orgs.). Ética e regulamentação na pesquisa antropológica. Brasília: Letras Livres e Editora da UnB, 2010.

FONSECA, C. Situando os comitês de ética em pesquisa: o sistema CEP (Brasil) em perspectiva. Horizontes Antropológicos, Porto Alegre, v. 21, n. 44, p. 333-369, jul./dez. 2015.

GUERRIERO, I. C. Z. O desafio da elaboração de diretrizes éticas específicas para Ciências Sociais e Humanas no Brasil. Revista Faculdad Nacional de Salud Pública, v. 23, p. 93-102, 2015.

. Resolução no 510, de 7 de abril de 2016, que trata das especificidades éticas das pesquisas nas ciências humanas e sociais e de outras que utilizam metodologias próprias dessas áreas. Ciência \& Saúde Coletiva, Rio de Janeiro, v. 21, n. 8, p. 2619-2629, ago. 2016.

GUERRIERO, I. C. Z.; DALLARI, S. G. The need for adequate ethical guidelines for qualitative health research. Ciência \& Saúde Coletiva, Rio de Janeiro, v. 13, n. 2, p. 303-311, abr. 2008.

GUERRIERO, I. C. Z.; BOSI, M. L.M. Ética em pesquisa na dinâmica do campo científico: desafios na construção de diretrizes para ciências humanas e sociais. Ciência \& Saúde Coletiva, Rio de Janeiro, v. 20, n. 9, p. 2615-2624, 2015.

GUERRIERO, I. C. Z.; MINAYO, M. C. de S. O desafio de revisar aspectos éticos das pesquisas em ciências sociais e humanas: a necessidade de diretrizes específicas. Physis: Revista de Saúde Coletiva, v. 23, n. 3, p. 763-782, jul./set. 2013.

LA FARE, M. de; MACHADO, F. V.; CARVALHO, I. C. M. Breve revisão sobre regulação da ética em pesquisa: subsídios para pensar a pesquisa em educação no Brasil. Práxis Educativa, Ponta Grossa, v. 9, n. 1, p. 247-283, jan./jun. 2014.

LIMA, A. B. de. Ética em pesquisa: implicações para a educação superior. Crítica Educativa, Sorocaba, v. 1, n. 1, p. 8-20, jan./jun. 2015.

MacRAE, E.; VIDAL, S. Resolução 196/96 e a imposição do modelo biomédico na pesquisa social: dilemas éticos e metodológicos do antropólogo pesquisando o uso de substâncias psicoativas. Revista de Antropologia, São Paulo, v. 49, n. 2, p. 645-666, jul./dez. 2006. 
MAINARDES, J. A ética na pesquisa em Educação: desafios atuais. In: CARVALHO, M. V. C. de; CARVAlHÊDO, J. L. P.; ARAUJO, F. A. M. Caminhos da Pós-Graduação em Educação no Nordeste do Brasil: avaliação, financiamento, redes e produção científica. Teresina: Edufpi, p. 73-82, 2016. Disponível em: $<$ https://www.researchgate.net/profile/Jefferson_Mainardes $>$. Acesso em: (?)

MAINARDES, J. Apresentação - Seção Temática "Ética na Pesquisa". Práxis Educativa, Ponta Grossa, v. 9, n. 1, p. 197-198, jan./jun. 2014.

MARRIEL, N. Comitês de ética em pesquisa: burocracia ou parceria? Uma visão pedagógica do papel educativo dos comitês no progresso das pesquisas. Revista de Educação do Cogeime, São Paulo, v. 16, n. 31, p. 21-36, dez. 2007.

MARTINS, E. C. de R. Vitam Impendere Vero: moral e verdade na pesquisa. Revista História e Perspectiva, Uberlândia, v. 28, n. 52, p.13-37, jan./jul. 2015.

MATTOS, D. O problema ético nas pesquisas em ciências humanas: metodologias, procedimentos e adequações legais. In: QUADROS JUNIOR, J. F. S. de (Org.). Discussões epistemológicas: ciências humanas sob uma ótica interdisciplinar. São Luís: Edufma, p. 61-85, 2016.

NOGUEIRA, V. M. R.; SILVA, V. R. da. Ética em pesquisa, Plataforma Brasil e a produção de conhecimento em ciências humanas e sociais. Ser Social, v. 14, n. 30, jan./jun. 2012.

NOVOA, P. C. R. O que muda na ética em pesquisa no Brasil: Resolução 466/12 do Conselho Nacional de Saúde. Einstein, São Paulo, v. 12, n. 1, p. 7-10, jan./mar. 2014.

SANTOS, L. A. C.; JEOLÁS, L. Apresentação: a pesquisa e sua ética, o poder e sua norma. Revista Brasileira de Sociologia, v. 3, n. 5, p. 1-23, jan./jun. 2015. (Dossiê - Comitês de Ética em Pesquisa: caminhos e descaminhos teórico-metodológicos).

SANTOS, L. A. de C.; JEOLÁS, L. Uma comissão nacional de ética em pesquisa, as ciências biomédicas e as ciências humanas: trespassing à brasileira. Revista Brasileira de Sociologia, v. 3, n. 5, p. 241-259, jan./jun. 2015.

SARTI, C. A ética em pesquisa transfigurada em campo de poder: notas sobre o sistema CEP/Conep. Revista Brasileira de Sociologia, Porto Alegre, v. 3, n. 5, p. 79-96, jan./jun. 2015.

SARTI, C.; DUARTE, L. F. D. (Orgs.). Antropologia e ética: desafios para a regulamentação; Brasília: ABA, 2013.

SCHMIDT, M. L. S. Ética e regramento em pesquisa nas ciências humanas e sociais. Revista Brasileira de Sociologia, v. 3, n. 5, p. 115-132, jan./jun. 2015.

SILVEIRA, R. A. T.; HÜNING, S. M. A tutela moral dos comitês de ética. Psicologia \& Sociedade, Florianópolis, v. 22, n. 2, p. 388-395, maio/ago. 2010.

SIQUELLI, S. A. Aspectos éticos em dissertações e teses do PPGE/UFSCar à luz da Resolução CNS 196/96. 2011. 116 f. Tese (Doutorado em Educação) - Universidade Federal de São Carlos, São Carlos, 2011.

Ética en investigación de educación y la Resolución 196/96: una realidad brasileña. REICE. Revista Iberoamericana sobre Calidad, Eficacia y Cambio en Educación, v. 11, n. 3, p. 111-122, 2013.

SIQUELLI, S. A.; HAYASHI, M. C. P. I. Ética em pesquisa de educação: uma leitura a partir da Resolução 196/96 com expectativas da Resolução 466/12. História e Perspectivas, Uberlândia, n. 52, p. 65-81, jan/jul. 2015.

Ética em pesquisa de educação no Brasil e Resolução 196/96 do Conselho Nacional da Saúde. In: ALMEIDA, L.; SILVA, B.; FRANCO, A. (Orgs). Livro de Atas do II Seminário Internacional "Contributos da Psicologia em Contextos Educativos". Braga/Portugal: Universidade do Minho, p. 90-100, 2012.

SOBOTTKA, E. A. Regulamentação, ética e controle social na pesquisa em ciências humanas. Revista Brasileira de Sociologia, v. 3, n. 05, p. 53-77, jan./jun. 2015.

TOMANIK, E. A. A ética e os comitês de ética em pesquisa com seres humanos. Psicologia em Estudo, Maringá, v. 13, n. 2, p. 395-404, abr./jun. 2008.

2 - Aplicação da ética na pesquisa em diferentes contextos educacionais (pesquisa com crianças, adolescentes, famílias, imagens, fracasso escolar, gênero e sexualidade, educação matemática) (27 textos)

BADARÓ, A. F. V. et al. Reflexões éticas e bioéticas apontadas nas pesquisas com crianças e adolescentes. Revista Eletrônica Gestão \& Saúde, Brasília, v. 6, n. 3, p. 2391-2407, jun. 2015.

BARBOSA, M. C. S. A ética na pesquisa etnográfica com crianças: primeiras problematizações. Práxis Educativa, Ponta Grossa, v. 9, n. 1, p. 235-245, jan./jun. 2014.

BONIN, I. T.; RIPOLL, D.; SANTOS, L. H. S. Ética, pesquisa e imagem de povos indígenas. Teias, Rio de Janeiro, v. 16, n. 42, p. 106-125, jul./set. 2015. 
CIAVATTA, M.; REIS, R.; ROSA, R. da. A ética na pesquisa e os comitês de ética sobre escritos e imagens. Teias, Rio de Janeiro, v. 16, n. 42, p. 7-23, jul./set. 2015.

DESSEN, M. A.; AVELAR, L. P. de; DIAS, R. L. S. Questões éticas na pesquisa com famílias. Paidéia, Ribeirão Preto, v. 8, n. 14-15, p. 169-180, fev./ago. 1998.

DORNELLES, L. V.; FERNANDES N. Estudos da criança e pesquisa com crianças: nuances luso-brasileiras acerca dos desafios éticos e metodológicos. Currículo sem Fronteiras, v. 15, n. 1, p. 65-78, jan./abr. 2015.

FERNANDES, N. Ética na pesquisa com crianças: ausências e desafios. Revista Brasileira de Educação, Rio de Janeiro, v. 21, n. 66, p. 759-779, jul./set. 2016.

FERRAÇO, C. E.; CARVALHO, J. M. Pensando as dimensões éticas, estéticas e políticas da produção e do uso de imagens nas pesquisas em educação. Teias, Rio de Janeiro, v. 16, n. 42, p. 24-36, jul./set. 2015.

FERREIRA, A.; SOUZA, A. Aspectos éticos nas pesquisas com adolescentes. Revista Bioética, Brasília, V. 20, n. 1, p. 56-59, 2012.

FERREIRA, M. "Ela é nossa prisioneira!" - Questões teóricas, epistemológicas e ético-metodológicas a propósito dos processos de obtenção da permissão das crianças pequenas numa pesquisa etnográfica. Reflexão e Ação, Santa Cruz do Sul, v. 18, n. 2, p. 151- 182, jul./dez. 2010.

FIORENTINI, D.; LORENZATO, S. Ética na pesquisa educacional: implicações para a Educação Matemática. In: FIORENTINI, D.; LORENZATO, S. Investigação em Educação Matemática: percursos teóricos e metodológicos. 3. ed. rev. Campinas: Autores Associados, 2009. p. 193-206.

GILBERTO, I. J. L. A imagem na pesquisa educacional e os princípios éticos da pesquisa. Teias, Rio de Janeiro, V. 16, n. 42, p. 115-124, jul./set. 2015.

KRAMER, S. Autoria e autorização: questões éticas na pesquisa com crianças. Cadernos de Pesquisa, São Paulo, n. 116, p. 41-59, jul. 2012.

FRANCISCHINI, R.; FERNANDES, N. Os desafios da pesquisa ética com crianças. Estudos de Psicologia, Campinas, v. 33, n. 1, p. 61-69, jan./mar. 2016.

LIMA, P. de M. Infância(s), alteridade e norma: dimensões para pensar a pesquisa com crianças em contextos não institucionais. Currículo sem Fronteiras, v. 15, n. 1, p. 94-106, jan./abr. 2015.

MARCELLO, F. de A. Infância-esquecimento e infância-viagem: Foucault e a ética da pesquisa com crianças. Currículo sem Fronteiras, v. 15, n. 1, p. 127-141, jan./abr. 2015.

MARQUES, D.; AMORIM, A. C. R. de. Ética, imanência e pesquisa menor. Teias, Rio de Janeiro, v. 16, n. 42, p. 37-48, jul./set. 2015.

NASCIMENTO, M. L. B. P. Como se conduz a pesquisa da infância quando a educação é mais um campo a compor seus estudos? Alguns elementos para discussão. Currículo sem Fronteiras, v. 15, n. 1, p. 79-93, jan./abr. 2015.

NETO, E. S.; ALVES, M. L. Implicações éticas da pesquisa educacional: reflexões a partir do problema do fracasso escolar. Revista @mbienteeducação, São Paulo, v. 5, n. 2, p. 152-162, jul./dez. 2012.

OLIVEIRA, T. R. M. Sobre a bicha do bem: queerizar a ética da pesquisa em educação. Educação \& Realidade, Porto Alegre, v. 41, n. 4, p. 1229-1250, out./dez. 2016.

PEREIRA, R. M. R. Por uma ética da responsividade: exposição de princípios para a pesquisa com crianças. Currículo sem Fronteiras, v. 15, n. 1, p. 50-64, jan./abr. 2015.

PÉREZ, C. L. V. Ora... Ora... Ora... A ética infantil e a pesquisa com as crianças e suas imagens. Teias, Rio de Janeiro, v. 16, n. 42, p. 49-69, jul./set. 2015.

QVORTRUP, J. A dialética entre a proteção e a participação. Currículo sem Fronteiras, v. 15, n. 1, p. 11-30, jan./abr. 2015.

SALGADO, M. M.; MÜLLER, F. A participação das crianças nos estudos da infância e as possibilidades da etnografia sensorial. Currículo sem Fronteiras, v. 15, n. 1, p. 107-126, jan./abr. 2015.

SARMENTO, M. J. Uma agenda crítica para os estudos da criança. Currículo sem Fronteiras, v. 15, n. 1, p. 31-49, jan./abr. 2015.

TREVISAN, G. Aprendizagens na construção de pesquisa com crianças e sobre as crianças. Currículo sem Fronteiras, v. 15, n. 1, p. 142-154, jan./abr. 2015.

ZAGO, L. F.; GUIZZO, B. S.; SANTOS, L. H. S. Problematizações éticas: inquietudes para a pesquisa em educação com gênero e sexualidade. Inter-Ação, Goiânia, v. 41, n. 1, p. 189-212, jan./abr. 2016. 


\section{3 - Fundamentos da ética na pesquisa (18 textos)}

CARVALHO, C. H. de; NETO, W. G. A formação do pesquisador e a dimensão ético-profissional. Revista História e Perspectiva, Uberlândia, v. 28, n. 52, p. 51-64, jan./jul. 2015.

DINIZ, D. Ética na pesquisa em ciências humanas - novos desafios. Ciência \& Saúde Coletiva, Rio de Janeiro, v. 13, n. 2, p. 417-426, mar./abr. 2008.

DINIZ, D.; SUGAI, A.; GUILHEM, D.; SQUINCA, F; (Orgs.). Ética em pesquisa: temas globais. Brasília: Editora UnB, 2008.

FRANCO, T. B. A ética em pesquisa e a estética do conhecimento. Revista Brasileira de Sociologia, v. 3, n. 5, p. 203-213, jan./jun. 2015.

GEWIRTZ, S. A reflexividade ética na análise de políticas: conceituação e importância. Práxis Educativa, Ponta Grossa, v. 2, n. 1, p. 7-12, jan./jun. 2007.

GOERGEN, P. L. A ética em pesquisa. Práxis Educativa, Ponta Grossa, PR, v. 10, n. 2, p. 301-315, jul./dez. 2015.

GRISOTTI, M. A ética em pesquisa com seres humanos: desafios e novas questões. Revista Brasileira de Sociologia, v. 3, n. 05, p. 159-175, jan./jun. 2015.

GUERRIERO, I. C. Z.; SCHMIDT, M. L. S.; ZICKER, F. Ética nas pesquisas em Ciências Humanas e Sociais na Saúde. São Paulo: Hucitec, 2008. (Contém capítulos sobre regulamentação).

GUILHEM, D.; DINIZ, D. O que é ética em pesquisa. São Paulo: Brasiliense, 2008.

KOTTOW, M. História da ética em pesquisa com seres humanos. Reciis - Revista Eletrônica de Comunicação, Informação \& Inovação em Saúde, Rio de Janeiro, v. 2, supl. 1, p. 7-18, dez. 2008.

LIMA, J. C. Ética da pesquisa e ética profissional em sociologia: um começo de conversa. Revista Brasileira de Sociologia, v. 3, n. 05, p. 215-239, jan./jun. 2015.

RAITZ, T. R.; FERREIRA, V. S.; GUERRA, A. F. Ética e metodologia: pesquisa na educação. Itajaí: Editora Univali, 2006.

SANTOS, L. Da competência no fazer à responsabilização no agir: ética e pesquisa em ciências hmanas. Práxis Educativa, Ponta Grossa, v. 12, n. 1, p. 1 -13, jan./abr. 2017. (ahead of print).

SARTI, F. M.; SANTOS, G. A. dos. Ética, pesquisa e políticas públicas. Rio de Janeiro: Rubio, 2010.

SEVERINO, A. J. Ética e pesquisa: autonomia e heteronomia na prática científica. Cadernos de Pesquisa, São Paulo, v. 45, n. 158, p. 776-792, out./dez. 2015.

Dimensão ética da investigação científica. Práxis Educativa, Ponta Grossa, v. 9, n. 1, p. 199-208, jan.jun. 2014.

SILVA, Telma C. (Org.). Ciclo de estudos e debates: procedimentos éticos e a pesquisa em Antropologia. Goiânia: Funape/UFG; Aba, 2014.

VÍCTORA, C. et al. (Orgs.). Antropologia e ética: o debate atual no Brasil. Niterói: Eduff, 2004. (Inclui capítulos sobre regulamentação).

\section{4 - Plágio e ética na publicação (cinco textos)}

DINIZ, D.; MUNHOZ, A. T. M. Cópia e pastiche: plágio na comunicação científica. Argumentum, Vitória, v. 3, p. 11-28, 2011.

KROKOSCZ, M. Abordagem do plágio nas três melhores universidades de cada um dos cinco continentes e do Brasil. Revista Brasileira de Educação, Rio de Janeiro, v. 16, n. 48, p. 745-818, set./dez. 2011.

KUHLMANN JR, M. Publicação em periódicos científicos: ética, qualidade e avaliação da pesquisa. Cadernos de Pesquisa, São Paulo, v. 44, n. 151, p. 16-32, jan./mar. 2014.

MORAES, R. O plágio na pesquisa acadêmica: a proliferação da desonestidade intelectual. Diálogos Possíveis, Salvador, n. 1, p. 91-109, jan./jul. 2004.

MUNHOZ, A. T. M.; DINIZ, D. Nem tudo é plágio, nem todo plágio é igual: infrações éticas na comunicação científica. Argumentum, Vitória, v. 3, p. 50-55, 2011.

\section{5 - Ética e formação de pesquisadores (dois textos)}

BESSA, J. C. R. Por uma cultura de ética e de integridade do pesquisador em formação inicial. Revista Espaço Acadêmico, v. 14, n. 159, p. 114-121, ago. 2014. 
NUNES, J. B. C. Formação de pesquisadores em educação para a ética em pesquisa. In: CARVALHO, M. V. C. de; CARVAlHÊDO, J. L. P.; ARAUJO, F. A. M. Caminhos da Pós-Graduação em Educação no Nordeste do Brasil: avaliação, financiamento, redes e produção científica. Teresina: Edufpi, 2016. p. 59-71.

\section{6 - Ética na prática da pesquisa (um texto)}

PAIVA, V. L. M. de O. Reflexões sobre ética e pesquisa. Revista Brasileira de Linguística Aplicada, Belo Horizonte, v. 5, n. 1, p. 43-61, 2005.

Recebido em 15-03-2017.

Aprovado em 22-05-2017. 